\title{
Frozen magma lenses below the oceanic crust
}

Mladen R. Nedimovic*, Suzanne M. Carbotte*, Alistair J. Harding ${ }^{\S}$, Robert S. Detrick ${ }^{\dagger}, J_{\text {. }}$ Pablo Canales ${ }^{\dagger}$, John B. Diebold*, Graham M. Kent ${ }^{\S}$, Michael Tischer* and Jeffrey M. Babcock $^{\S}$

*Lamont-Doherty Earth Observatory of Columbia University, 61 Route 9W, P. O. Box 1000, Palisades, NY, 10964-8000, USA

${ }^{\S}$ Scripps Institution of Oceanography, UCSD, 9500 Gilman Drive, La Jolla, CA 920930225, USA

${ }^{\dagger}$ Woods Hole Oceanographic Institution, 360 Woods Hole Rd., Woods Hole, MA 025431542, USA

The Earth's oceanic crust crystallizes from magmatic systems generated at midocean ridges. Whereas a single magma body residing within the mid-crust is responsible for the generation of the upper oceanic crust, it remains unclear if the lower crust is formed from the same magma body, or it primarily crystallizes from magma lenses located at the base of the crust ${ }^{1-3}$. Thermal modelling ${ }^{4-6}$, tomography $^{7}$, compliance $^{8}$ and PmS wave studies ${ }^{9}$, supported by the geologic evidence ${ }^{3,10-18}$, suggest the presence of gabbroic-melt accumulations within the Moho transition zone (MTZ) in the vicinity $(\sim 10-20 \mathrm{~km})$ of fast- to intermediate-spreading centres. However, no reflection images have yet been obtained of such structure within the MTZ. Here we show the first images of groups of MTZ reflection events that resulted from our analysis of $\sim 1500 \mathrm{~km}$ of multichannel seismic data collected across the intermediatespreading (55 mm/yr) ${ }^{19}$ Juan de Fuca ridge. Our observations suggest that gabbro lenses and melt accumulations embedded within dunite or residual mantle peridotite 


\section{are the most probable cause for the observed MTZ reflectivity, hence providing support for the crustal generation hypothesis from multiple magma bodies.}

The MTZ, located at the crust-mantle boundary, separates layered gabbros of the crust derived by magma crystallization, from residual peridotites, generally harzburgites, representing mantle rocks ${ }^{10,12}$. Mapping of the Oman and the Bay of Islands ophiolite complexes, both of which are inferred to be composed of obducted oceanic lithosphere formed at intermediate- to fast-spreading ridges, has shown that the MTZ is composed of sills and lenses of gabbro intruded into dunite or, occasionally, into hazburgite ${ }^{3,10-18}$. The thickness of the MTZ can vary from a few meters to over two kilometres ${ }^{10,12}$. A thin MTZ $(<\sim 100 \mathrm{~m})^{17}$ is widespread within the mapped ophiolites and is characterized by intense deformation resulting from solid-state flow away from the ridge axis that transposes all lithologic units into parallelism sub-horizontal to the Moho. In the few areas where a localized, thick MTZ $(>\sim 100 \mathrm{~m})^{17}$ is observed, individual gabbro sills and lenses can reach thicknesses of a few hundred meters ${ }^{12}$. Locally steep orientation of foliation planes and lineations within high-temperature peridotite led to the association of thick MTZs of the Oman ophiolite with preserved ancient mantle diapirs, many of which are centered along inferred paleo-ridge axes ${ }^{16}$. Gabbro sills of the thick MTZ display strong magmatic flow structure, with lineations and foliations parallel to those within the surrounding peridotites where solid-state conditions prevailed. These structures were formed during the horizontal flow carrying upper mantle formations away from the ridge axis ${ }^{13}$.

In our Juan de Fuca reflection sections, the Moho discontinuity is imaged along more than $60 \%$ of the survey track (Fig. 1). Because the inferred crustal thickness is remarkably uniform, as inferred from two-way travel times $(2080 \pm 100 \mathrm{~ms})$, the stratigraphic level of events originating within the MTZ is well constrained. The Moho discontinuity is mostly 
represented by a single reflection event of variable strength, at places remarkably sharp and strong (Fig. 2a). Seismic modelling studies ${ }^{11,20}$, suggest that areas with a single strong or moderately strong Moho reflection event are likely characterized by an abrupt passage from layered gabbros of the lower crust, to residual peridotites of the uppermost mantle. Areas with weak or no Moho reflection event may be indicative of rough Moho topography that scatters acoustic energy, or may represent thick MTZs composed of thin alternating gabbro and dunite sills, where the ratio of dunite to gabbro gradually increases with depth resulting in a gradual downward velocity increase (Supplementary Discussion 1).

In Fig. 2b, we show the largest and the most prominent group of MTZ reflection events recorded (Supplementary Discussion 2). These sub-horizontal reflections are located on line 17-3-1, more than $30 \mathrm{~km}$ east of the ridge axis (Fig. 1). The Moho reflection event in this section of line 17-3-1 is weak but traceable, placing the recorded events just below the crust. (For the purposes of discussion and following ref. 12, we assume that the geophysical Moho and petrological Moho are equivalent, and that the MTZ is therefore the uppermost part of the mantle.) The spatial character of the imaged subcrustal reflection events is in excellent agreement with the geometry of the thick MTZ as described by ophiolite studies $^{12}$. The anomalous MTZ area is some $10 \mathrm{~km}$ wide, with individual bright events showing 4-5 km of lateral continuity and combined thickness of over $2000 \mathrm{~m}$ in the central region, comparable to the maximum thickness mapped in ophiolites ${ }^{10,12}$.

High signal-to-noise ratio of the imaged MTZ events presented in the migrated stack of Fig. $2 b$ indicates that these reflections likely arise at sharp boundaries between layers of significantly different physical properties. The strength of the observed sub-Moho events may also be partially due to constructive interference from the top and the bottom sill reflections. Assuming that the MTZ events are caused by gabbro sills with a P-wave 
velocity of $7 \mathrm{~km} / \mathrm{s}$, and that the dominant data signal frequency is $\sim 10-15 \mathrm{~Hz}$, the strongest responses will be generated by gabbro sills with thicknesses from $\sim 50-150 \mathrm{~m}$, and will be characterized by single reflection events. This is in good agreement with the thickness of large gabbro sills mapped in ophiolites. Sills with thicknesses $<\sim 20 \mathrm{~m}$ cannot be imaged because of destructive wave interference, and sills with a thickness $>\sim 200 \mathrm{~m}$ should be characterized by paired top and bottom reflection events of opposite polarity, which does not appear to be the case in our images.

Insight about the lithologies causing the reflections can in principle be obtained by analysis of reflection amplitude variation as a function of offset or angle of incidence (AVO/AVA). However, the signal-to-noise ratio of our prestack data is much too low for the standard AVO analysis. We therefore compute trace envelopes (Fig. 3a) for a partially stacked super CMP gather positioned over the brightest group of subcrustal reflections from Fig. 2b, and compare them with calculated amplitude curves for rays reflected from the potential rock interfaces of a thick MTZ (Fig. 3b-f) (Supplementary Discussion 3). The observed reflection strength of the MTZ events appears to gradually weaken with the increasing source-receiver offset, with somewhat greater amplitude drop at offsets larger than about $4 \mathrm{~km}$. Based on the relationship between modelled and observed reflection strength curves (red and blue lines in Figs $3 \mathrm{~b}$ and 3c), we speculate that the imaged reflections were generated at contacts between solid gabbro sills and host dunite, a structural relationship frequently observed in the thick MTZs of the Oman ophiolite ${ }^{13}$. We cannot resolve (see Fig. 3) whether the host rock for the gabbro sills is dunite or residual mantle peridotite ${ }^{3}$.

The possibility that the strongest MTZ reflections in Fig. 3a were generated at the contact between ultramafic host rocks and gabbro-melt, however, cannot be eliminated. 
Nevertheless, such an interface is less likely because the ridge axis is located at a significant distance westward $(\sim 33 \mathrm{~km})$, and the predicted reflection amplitude fall-off with offset for a dunite - gabbro-melt interface seems more rapid than that observed (Fig. 3b). Moreover, the reflection amplitudes for the dunite - gabbro-melt contact (Fig. 3b) are much larger than for the corresponding solid-solid interface (Fig. 3c) but high signal-to-noise ratio subcrustal reflections are not identified in the prestack data. The graph shown in Fig. 3f indicates that the lower boundary of thick MTZs, usually represented by a transition from dunite to harzburgite, is transparent for reflection imaging.

In addition to the events shown in Fig. 2b, we were able to identify a number of other areas with complex Moho and sub-Moho reflections along our survey track (Supplementary Discussion 4). The distribution of all imaged subcrustal reflection areas extending for at least some $3 \mathrm{~km}$, is presented in Fig. 1. The identified thick MTZs form two distinct groups; those centered near the ridge axis and those found beyond $(>\sim 20 \mathrm{~km})$, like the one shown in Fig. 2b. The thick MTZs found near the ridge axis appear to be uniformly and even symmetrically distributed across the ridge axis. An example of a series of subcrustal reflection events located less than $10 \mathrm{~km}$ from the ridge axis on line 87-89-7389a is shown in Fig. 4. Although our data do not provide direct constraints on the lithologic nature of the subcrustal interfaces imaged in the vicinity of the ridge axis, ophiolite studies $^{3,15,17}$ and other geophysical investigations ${ }^{7-9}$ indicate that gabbro-melt lenses are emplaced in the MTZ near the ridge axis. Therefore, the observed subcrustal reflections, such as those presented in Fig. 4, are more likely generated at the interface between ultramafic rocks and gabbro-melt than the subcrustal reflections located farther away from the ridge axis. 
Away from ridge axis $(>\sim 20 \mathrm{~km})$, the instances of thick MTZs appear to correlate with the location of outer propagator wakes defined by magnetic isochrons (Fig. 1). The general absence of detectable thick MTZs away from the ridge axis, and outside of the outer propagator wake area, suggests a highly dynamic environment at the crust-mantle boundary up to a distance of a few tens of kilometres from the spreading center. Within this area, MTZ gabbro sills and dunite layers both form and can cease to exist. Structural mapping of the Oman ophiolite provides evidence for two possible mechanisms responsible for thinning of the thick MTZs: Tectonic stretching and upward magma discharge ${ }^{17,3}$.

The thick MTZs found $>\sim 20 \mathrm{~km}$ away from the ridge axis, and in particular the largest ones marked in red in Fig. 1, are distinct from the near ridge axis features in size, shape and thickness. Based on their spatial association with the outer propagator wakes, we suggest that these preserved thick MTZs were formed by intrusion of melt into the crustmantle boundary area within the zone of active spreading on the propagating ridge segment. At the propagator tips, the spreading breaks into a relatively cool lithosphere that could allow for large magma bodies to be emplaced and solidified. Ophiolite mapping and our data constrain the maximum thickness of emplaced magma bodies to $\sim 150-200 \mathrm{~m}$, and their maximum diameter to several kilometres. Existence of isolated magma bodies at propagator tips, which appear to have experienced rapid cooling and high fractional crystallization, is supported by the common occurrence of high amplitude magnetic anomalies and high Fe-Ti basalts ${ }^{21,22}$. Large intrusions of basaltic melt into previously accreted, and therefore older and colder oceanic lithosphere are also documented in the Maqsad diapir area of the Oman ophiolite ${ }^{23,24}$, and were associated with the opening of a propagator $^{18}$. Two of the imaged thick MTZs (marked red in Fig. 1), characterized by strong reflection events that we believe are indicative of the thick ( $\sim 50-150 \mathrm{~m})$ gabbro sills, could also be associated with diapirism linked to opening of the propagators. In both cases 
the imaged sills appear to have a ridgeward dip and to be located within the newly accreted crust, which itself is characterized by smoothest topography suggesting locally abundant melt supply. Unlike the crust forming the inside wakes, which is rotated and sheared ${ }^{21}$, the crust forming the outer propagator wakes experiences little deformation ${ }^{22}$ and therefore provides a sheltered environment in which thick MTZs may be preserved. Interestingly, of the three MTZ melt lenses identified along the East Pacific Rise $11^{0}-13^{0} \mathrm{~N}$ area using PmS waves $^{9}$, two are associated with the outer wakes of migrating overlapping spreading centers.

Our evidence suggests that sill emplacement in the MTZ may be a common feature beneath intermediate spreading centers but the sills themselves are short-lived. Only sills within the thick MTZs formed at propagator tips appear to remain preserved after being accreted to outer propagator wakes. The melt lenses forming these thick MTZs are thought to have experienced repetitious magma expulsion with continuous melt replenishment ${ }^{3,15}$. Hence, the interpreted large gabbro-melt sills within the thick MTZ shown in Fig. 2b perhaps represent first images of frozen subcrustal magma chambers.

1. Sinton, J. M. \& Detrick, R. S. Mid-ocean ridge magma chambers. J. Geophys. Res. 97, 197-216 (1992).

2. Phipps Morgan, J. \& Chen, Y. J. The genesis of oceanic crust; magma injection, hydrothermal circulation, and crustal flow. J. Geophys. Res. 98, 6283-6297 (1993).

3. Kelemen, P. B. \& Aharonov, E. Periodic formation of magma fractures and generation of layered gabbros in the lower crust beneath oceanic spreading ridges. In Faulting and Magmatism at Mid-Ocean Ridges, W. R. Buck, P. T. Delaney, J. A. Karson and Y. Lagabrielle, Eds. (Geophysical Monograph 106, AGU, Washington DC), 267-289 (1998). 
4. Garrido, C. J., Kelemen, P. B. \& Hirth, G. Variation of cooling rate with depth in lower crust formed at an oceanic spreading ridge: Plagioclase crystal size distributions in gabbros from the Oman ophiolite. Geochem. Geophys. Geosyst. 2, 2000GC000136 (2001).

5. Cherkaoui, A. S. M., Wilcock, W. S. D., Dunn, R. A. \& Toomey, D. R. A numerical model of hydrothermal cooling and crustal accretion at a fast spreading mid-ocean ridge. Geochem. Geophys. Geosyst. 4, $2001 \mathrm{GC000215}$ (2003).

6. Maclennan, J., Hulme, T. \& Singh, S. C. Thermal models of oceanic crustal accretion: Linking geophysical, geological and petrological observations. Geochem. Geophys. Geosyst. 5, 2003GC000605 (2004).

7. Dunn, R. A., Toomey, D. R., Detrick, R. S. \& Wilcock, W. S. D. Continuous mantle melt supply beneath an overlapping spreading center on the East Pacific Rise, Science 291, 1955-1958 (2001).

8. Crawford, W. C. \& Webb, S. C. Variations in the distribution of magma in the lower crust and at the Moho beneath the East Pacific Rise at $9^{0}-10^{0}$ N. Earth Planet. Sci. Lett. 203, 117-130 (2002).

9. Garmany, J. Accumulations pf melt at the base of young oceanic crust. Nature 340, 628632 (1989).

10. Karson, J. A., Collins, J. A. \& Casey, J. F. Geologic and seismic velocity structure of the crust/ mantle transition in the Bay of Islands ophiolite complex. J. Geophys. Res. 89, 6126-6138 (1984).

11. Collins, J. A., Brocher, T. M. \& Karson, J. A. Two-dimensional seismic reflection modeling of the inferred fossil oceanic crust/mantle transition in the Bay of Islands Ophiolite. J. Geophys. Res. 91, 12520-12538 (1986). 
12. Benn, K., Nicolas, A. \& Reuber, I. Mantle-crust transition zone and origin of wehrlitic magmas; evidence from the Oman Ophiolite. Tectonophysics 151, 75-85 (1988).

13. Boudier, F. \& Nicolas, A. Nature of the Moho transition zone in the Oman ophiolite. $J$. Petrol. 36, 777-796 (1995).

14. Boudier, F., Nicolas, A. \& Ildefonse, B. Magma chambers in the Oman Ophiolite; fed from the top and the bottom. Earth Planet. Sci. Lett. 144, 239-250 (1996).

15. Korenaga, J. \& Kelemen, P. B. Origin of gabbro sills in the Moho transition zone of the Oman Ophiolite; implications for magma transport in the oceanic lower crust. J. Geophys. Res. 102, 27729-27749 (1997).

16. Nicolas, A., Boudier, F., Ildefonse, B. \& Ball, E. Accretion of Oman and United Arab Emirates ophiolite; discussion of a new structural map. Mar. Geophys. Res. 21, 147-179 (2000).

17. Jousselin, D. \& Nicolas, A. The Moho transition zone in the Oman Ophiolite; relation with wehrlites in the crust and dunites in the mantle. Mar. Geophys. Res. 21, 229-241 (2000).

18. Godard, M., Jousselin, D. \& Bodinier, J-L. Relationships between geochemistry and structure beneath a paleo-spreading centre; a study of the mantle section in the Oman Ophiolite. Earth Planet. Sci. Lett. 180, 133-148 (2000).

19. Wilson, D. S. Confidence intervals for motion and deformation of the Juan de Fuca Plate. J. Geophys. Res. 98, 16053-16071 (1993).

20. Brocher, T. M., Karson, J. A. \& Collins, J. A. Seismic stratigraphy of the oceanic Moho based on ophiolite models. Geology 13, 62-65 (1985). 
21. Hey, R., Duennebier, F. K. \& Morgan, W. J. Propagating rifts on midocean ridges. J. Geophys. Res. 85, 3647-3658 (1980).

22. Hey, R., Kleinrock, M. C., Miller, S. P., Atwater, T. M. \& Searle, R. C. Sea Beam/ deep-tow investigation of an active oceanic propagating rift system, Galapagos $95.5 \mathrm{~W} . J$. Geophys. Res. 91, 3369-3393 (1986).

23. Ceuleneer, G., Monnereau, M. \& Amri, I. Thermal structure of a fossil mantle diapir inferred from the distribution of mafic cumulates. Nature 379, 149-153 (1996).

24. Amri, I., Benoit, M. \& Ceuleneer, G. Tectonic setting for the genesis of oceanic plagiogranites; evidence from a paleo-spreading structure in the Oman Ophiolite. Earth Planet. Sci. Lett. 139, 177-194 (1996).

25. Carlson, R. L. Rocks and Earth's crust. In Handbook of Elastic Properties, Liquids, and Gases, M. Levy, H. Bass, and R. Stern, Eds. (Academic Press, New York), 377-461 (2001).

Supplementary information accompanies the paper on www.nature.com/nature.

Acknowledgements We are grateful to P. B. Kelemen and W. R. Buck for their reviews. Kris Vasudevan provided us with a stacked section of the Canadian line 1989-15, shown in Supplementary Information section. The Doherty and National Science Foundations supported this work.

Competing interests statement The authors declare that they have no competing financial interests.

Correspondence and requests should be addressed to M.R.N. (e-mail: mladen@1deo.columbia.edu.).

Fig. 1. Strength of the Moho reflection event for the 2002 Juan de Fuca ridge flank seismic profiles is plotted in color over a sun-illuminated gray bathymetry map. Dark blue - strong Moho reflection; bright blue - moderate Moho reflection; green - weak Moho reflection; white - no Moho reflection. From north to south, seismic 
profiles cross Endeavour, Northern Symmetric and Cleft ridge segments. Every five thousandth common midpoint (CMP), corresponding to distance of $31.25 \mathrm{~km}$, is annotated along each profile. Thick red and orange line segments mark sections characterized by sub-Moho reflection events. Red color marks the MTZ reflection events that are imaged at a high signal to noise ratio. Thick black lines are the interpreted traces of the ridge axis. Thin purple lines are magnetic isochrons ${ }^{19}$. Overlay areas approximately outline the location of inner and outer propagator wakes. The inset shows the location of the study area with respect to North America.

Fig. 2. Two $20 \mathrm{~km}$-long sections, one of line 34-32 reflection image (part a) and the other of line 17-3-1 reflection image (part b), are shown using grayscale variable density plots. The distance to depth ratio is approximately $1: 1$. Oceanic crustal structure in both sections is imaged remarkably well. Part (a) is characterized by a mostly continuous and sharp image of the igneous basement surface, the layer 2A/2B boundary and the Moho discontinuity. Part (b) shows all the same events as part (a) but differs from it because it also includes a set of sub-Moho reflections, and because it is characterized by a weaker Moho reflection and a layer $2 \mathrm{~A} / 2 \mathrm{~B}$ boundary event that is not imaged across the whole section. Weak events found a few hundred milliseconds below the layer 2A/2B boundary, that may appear to be related to the boundary between the layer $2 \mathrm{~B}$ and layer 3 , are processing artifacts caused by merging of sections with a different content of signal frequencies. The upper parts of the sections include all recorded signal frequencies (2-7-100-125 $\mathrm{Hz}$ ). To improve the Moho reflection event, only the low signal frequencies (2-7-20$40 \mathrm{~Hz}$ ) are kept for the deeper parts of the sections. For details about the data acquisition and processing see Supplementary Methods 1 and 2 . 
Fig. 3. (a-f) Modeled and measured reflection amplitude versus offset dependence for the MTZ events shown in Fig. 2b. (a) Trace envelope of the partially stacked super CMP gather 18340-18360. The super gather is composed of 21 adjacent CMP gathers approximately centered at the middle of the group of bright subcrustal reflection events shown in Fig. 2b. Gather data traces were amplitude corrected only for the geometrical propagation effects and shot and receiver "surface" inconsistencies, sorted to $1 \mathrm{~km}$-wide partial source-receiver offset gathers and stacked. To estimate the signal reflection strength as a function of arrival time, the partial stacked super gather data were then transformed to trace envelope and plotted in color. (b-f) Ray amplitude, in red, as a function of the source-receiver offset for the potential rock interfaces of the thick MTZ shown in Fig. $2 b$ (Supplementary Methods 3). Lithologic interfaces were formed by superimposing gabbro $\left(V_{p}=7000 \mathrm{~m} / \mathrm{s} ; V_{s}=3750 \mathrm{~m} / \mathrm{s} ; \square=2900 \mathrm{~kg} / \mathrm{m}^{3}\right)$, dunite $\left(V_{p=} 8450 \mathrm{~m} / \mathrm{s} ; V_{s}=4850\right.$ $\left.\mathrm{m} / \mathrm{s} ; \quad \square=3300 \mathrm{~kg} / \mathrm{m}^{3}\right)$, harzburgite $\left(\mathrm{V}_{\mathrm{p}}=8300 \mathrm{~m} / \mathrm{s} ; \mathrm{V}_{\mathrm{s}}=4850 \mathrm{~m} / \mathrm{s} ; \quad \square=3300 \mathrm{~kg} / \mathrm{m}^{3}\right)$, wehrlite $\left(V_{p}=8100 \mathrm{~m} / \mathrm{s} ; V_{s}=4650 \mathrm{~m} / \mathrm{s} ; \square=3300 \mathrm{~kg} / \mathrm{m}^{3}\right)$, and gabbro melt $\left(V_{p}=3200\right.$ $\left.\mathrm{m} / \mathrm{s} ; V_{\mathrm{s}}=0 \mathrm{~m} / \mathrm{s} ; \quad \square=2900 \mathrm{~kg} / \mathrm{m}^{3}\right)^{10,25}$. For the inverted interfaces of Fig. 3b-f, only the sign (polarity) of the reflection amplitudes changes. Solid and dashed blue lines in (b) and (c) are the cubic fit to the average maximum amplitude for the events shown in (a) and the computed error bounds, respectively. The observed amplitude decay curve is scaled so that it matches (b) and (c) modeled amplitudes at zero-offset.

Fig. 4. A series of subcrustal reflection events recorded on line 87-89-73-89a is displayed at the distance to depth ratio of about 1:1. The reflection events are located some 7 to $8 \mathrm{~km}$ east of the ridge axis (Fig. 1) and a few hundred ms below the Moho reflection event, which in this section of line $87-89-73-89$ a is of moderate 
strength. Our interpretation of the Moho discontinuity location is shown with a continuous red line; dashed where inferred. The yellow line is the igneous basement pick delayed by $2300 \mathrm{~ms}$, the average two-way travel time through the crust in the vicinity of the Cleft ridge. The presented events appear to exhibit a very mild dip away from the axis but the form and strength of these sub-Moho reflections might be imaged inaccurately due to focusing and defocusing of the acoustic energy in the areas close to the ridge axis, where the seafloor topography is generally rougher. Nevertheless, the recorded signals are likely true sub-Moho reflections as we generally do not observe scattered energy at earlier times, and cannot find an explanation for its focusing only just below the Moho discontinuity. 
Nedimovic et al., Fig. 1

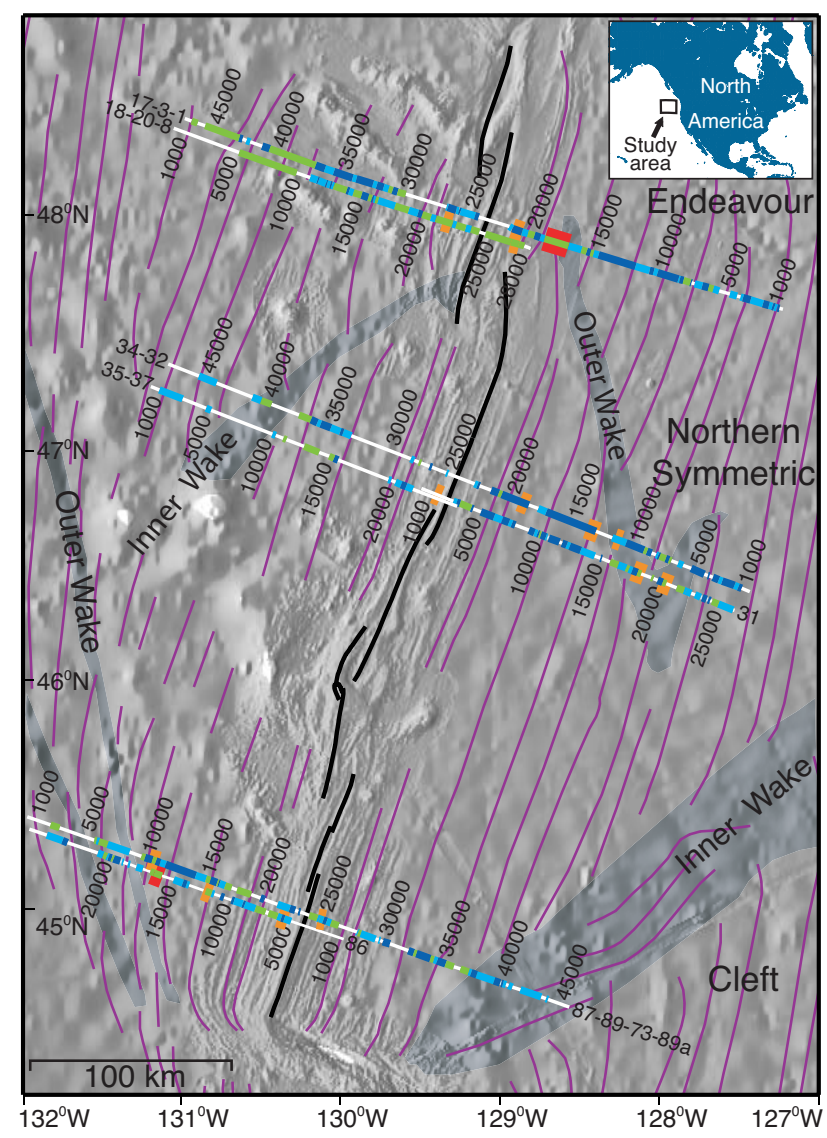


Nedimovic et al., Fig. 2

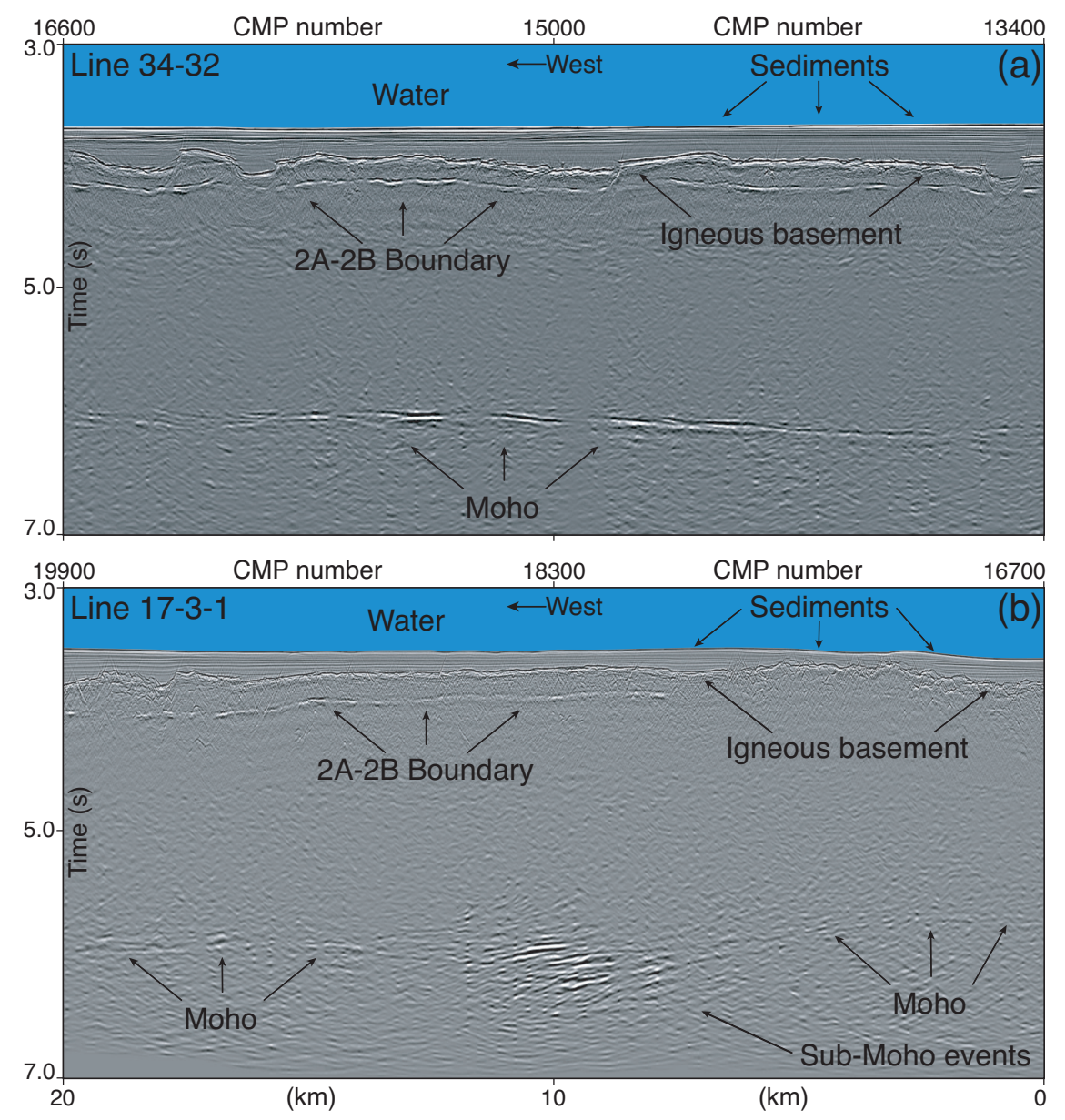


Nedimovic et al., Fig. 3

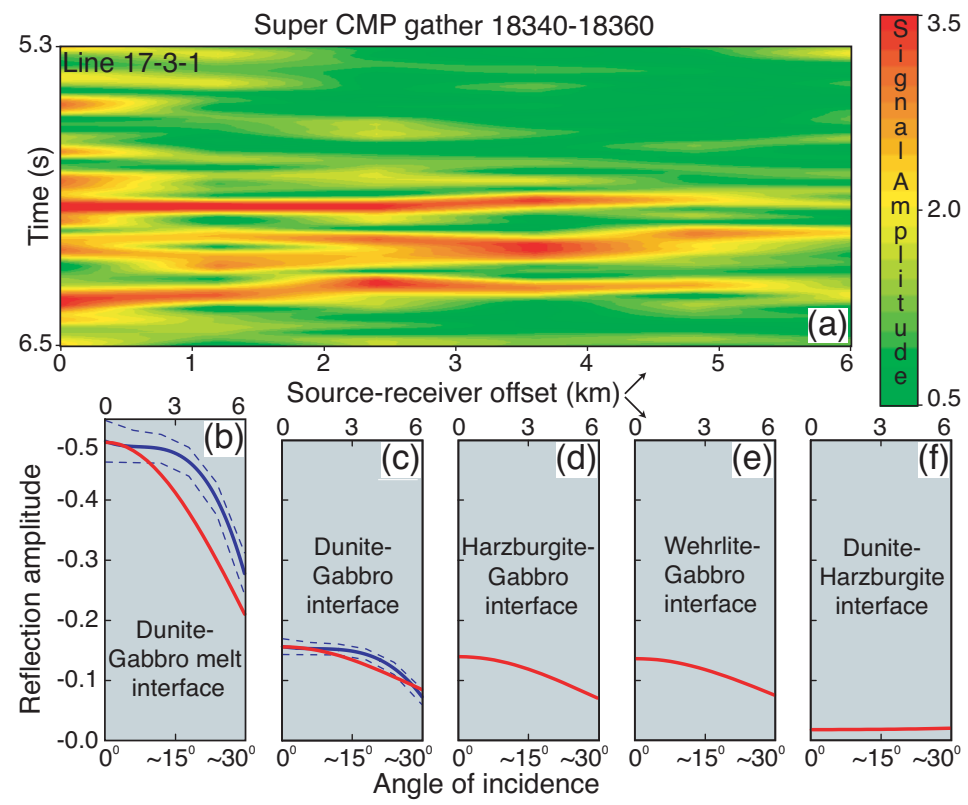


Nedimovic et al., Fig. 4

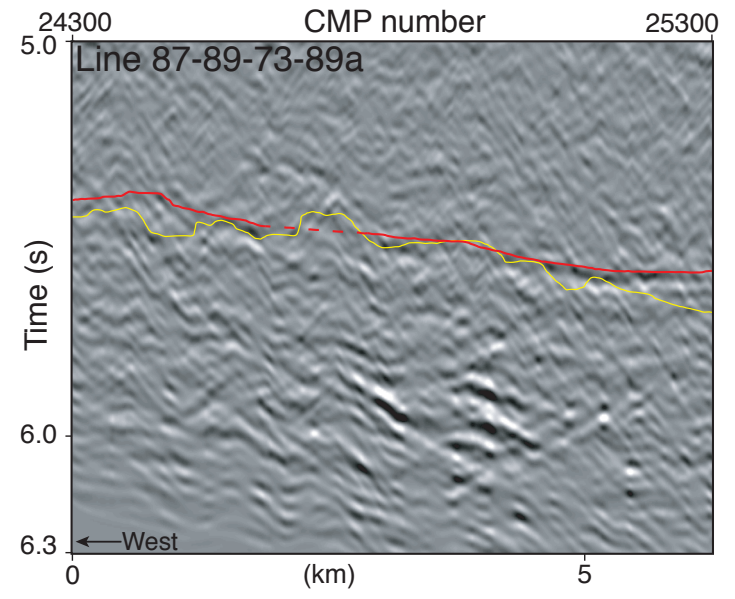




\section{Supplementary Information}

\section{Supplementary Methods}

1. Data acquisition. The data used for this study were collected in 2002 on $R / V$ Ewing during the EW0207 cruise using a $6 \mathrm{~km}$-long, 480 channel Syntron digital streamer with receiver groups spaced at $12.5 \mathrm{~m}$. Streamer depth and feathering were monitored with a mix of 13 depth controlling and 11 compass-enhanced DigiCourse birds, plus a GPS receiver on the tail buoy. A 10-element, 49.2 L (3005 $\left.\mathrm{in}^{3}\right)$ tuned airgun array was used as the source of acoustic energy with shot-by-distance at a $37.5 \mathrm{~m}$ spacing. Listening time was $10.24 \mathrm{~s}$ and sampling rate 2 ms. Data were recorded on 3490e tapes in SEGD format using the Syntron Syntrack 480 seismic data acquisition system. The recorded signal has a bandwidth ranging from a couple to over $100 \mathrm{~Hz}$. The nominal common midpoint (CMP) bin spacing is $6.25 \mathrm{~m}$ and the data trace fold is 81 .

2. Data processing. The prestack processing strategy adopted for the EW0207 multichannel seismic (MCS) data consisted of: Standard straight-line CMP bin geometry; F-K and bandpass (2-7-100-125 Hz) filtering to remove the low frequency cable noise; amplitude correction for geometrical spreading; surface consistent minimum phase predictive deconvolution to balance the spectrum and remove short period multiples; surface consistent amplitude correction to correct for anomalous shot and receiver-group amplitudes not related to wave propagation; trace editing; velocity analysis using the velocity spectrum method; normal moveout and dip moveout corrections to align signal for stacking; and CMP mute to remove overly stretched data. The prepared prestack data, with and without the automatic gain control, were then stacked (averaged). The poststack processing included seafloor mute, primary multiple mute to reduce migration noise, bandpass filtering $(2-7-100-125 \mathrm{~Hz})$ and time migration to collapse diffractions and position the recorded reflection events to their true 
subsurface locations. Extracting an image of the layer 2A/2B boundary, often referred to as the $2 \mathrm{~A}$ event, requires a somewhat different processing scheme because this event is not a true reflection ${ }^{1}$. The prestack data preparation is identical up to the velocity analysis, which is done on bandpass filtered $(2-7-40-60 \mathrm{~Hz})$ constant velocity stacks. When the normal moveout velocities that best flatten the retrograde branch of the $2 \mathrm{~A}$ refraction are chosen, the data are stacked. The stacked layer 2A event is time migrated and coherency filtered. Surgical mute is then used to extract the layer $2 \mathrm{~A}$ event, which is afterwards merged with the reflection section to form the final, composite seismic image.

3. Modeling. The synthetic ray-amplitude curves for a variety of potential MTZ interfaces shown in Fig. 3b-f were calculated by ray tracing through a 1D layered media. Modelled amplitudes depend on both the reflection and transmission coefficients but are scaled before plotting to equal the reflection coefficient at zero-offset. The 1D model used for ray tracing was constructed for the area centered at the largest group of MTZ reflection events imaged (Figs 2b and S1). Maximum source-receiver offset was $6000 \mathrm{~m}$, identical to that of the field data. The thickness $(d)$, P-wave velocity $\left(V_{p}\right)$, S-wave velocity $\left(V_{s}\right)$ and density $(\square)$ for each layer were estimated both from the two-way travel times and velocities extracted from the seismic reflection data, and from the published material describing the oceanic crust and referenced in the main body of the text. The media above the modelled MTZ interfaces consists of: (1) Water layer, $\mathrm{V}_{\mathrm{p}}=1490 \mathrm{~m} / \mathrm{s}, \mathrm{V}_{\mathrm{s}}=0 \mathrm{~m} / \mathrm{s}, \mathrm{G}=1000 \mathrm{~kg} / \mathrm{m}^{3}, \mathrm{~d}=2620 \mathrm{~m}$; sediment layer $1, V_{\mathrm{p}}=1620 \mathrm{~m} / \mathrm{s}, \mathrm{V}_{\mathrm{s}}=935 \mathrm{~m} / \mathrm{s}, \mathrm{V}=1650 \mathrm{~kg} / \mathrm{m}^{3}, \mathrm{~d}=80 \mathrm{~m}$; sediment layer $2, \mathrm{~V}_{\mathrm{p}}=1950 \mathrm{~m} / \mathrm{s}$, $\mathrm{V}_{\mathrm{s}}=1126 \mathrm{~m} / \mathrm{s}, \square=2000 \mathrm{~kg} / \mathrm{m}^{3}, \mathrm{~d}=90 \mathrm{~m}$; layer $2 \mathrm{~A}$ (basaltic extrusives), $\mathrm{V}_{\mathrm{p}}=3000 \mathrm{~m} / \mathrm{s}, \mathrm{V}_{\mathrm{s}}=1732$ $\mathrm{m} / \mathrm{s}, \square=2400 \mathrm{~kg} / \mathrm{m}^{3}, \mathrm{~d}=400 \mathrm{~m}$; layer $2 \mathrm{~B}$ (diabase dikes), $\mathrm{V}_{\mathrm{p}}=5500 \mathrm{~m} / \mathrm{s}, \mathrm{V}_{\mathrm{s}}=3176 \mathrm{~m} / \mathrm{s}, \square=2750$ $\mathrm{kg} / \mathrm{m}^{3}, \mathrm{~d}=2000 \mathrm{~m}$; layer 3 (gabbros), $\mathrm{V}_{\mathrm{p}}=6850 \mathrm{~m} / \mathrm{s}, \mathrm{V}_{\mathrm{s}}=3955 \mathrm{~m} / \mathrm{s}, \square=2900 \mathrm{~kg} / \mathrm{m}^{3}, \mathrm{~d}=3600 \mathrm{~m}$; upper MTZ (thin alternating layers of gabbro and dunite or harzburgite), $\mathrm{V}_{\mathrm{p}}=7650 \mathrm{~m} / \mathrm{s}$, $\mathrm{V}_{\mathrm{s}}=4417 \mathrm{~m} / \mathrm{s}, \square=3100 \mathrm{~kg} / \mathrm{m}^{3}, \mathrm{~d}=750 \mathrm{~m}$. The deepest thin layer in the upper MTZ is also the 
upper layer of the investigated interface in Fig. 3b-f. We test the robustness of our modelled amplitudes by varying physical properties of layer $2 \mathrm{~A}$, whose velocity and density are likely to be the least well constrained. Variation of $\pm 33 \%$ in physical properties of layer $2 \mathrm{~A}$ has a large effect on the calculated absolute amplitudes but little effect on the relative drop-off of amplitudes as a function of angle of incidence. The difference in the amplitude drop-off is less than $2 \%$ and the maximum angle of incidence at the investigated MTZ interface changes by only $\sim 1 / 3$ of a degree. We also varied the average thickness of the upper MTZ layer. Variation in the average thickness of $300 \mathrm{~m}$ changes the maximum angle of incidence, for the 6000 m-long streamer, by only $\sim 1.5$ degrees. The tested large changes in the model have little effect on the fall-off or shape of the synthetic amplitude curves and show the robustness of our results based on the true relative amplitudes. Estimating true absolute amplitudes has the potential to provide additional interpretational information but we cannot carry out such a study because the signal to noise ratio of our data is too low. Furthermore, the true absolute amplitudes are very sensitive to the characteristics of the media through which the waves propagate and we lack sufficiently accurate constraints needed to estimate these amplitudes.

\section{Supplementary Discussion}

1. Moho reflection character. Seismic modelling studies ${ }^{2,3}$, based on lithospheric crosssections through ophiolite complexes formed at intermediate and fast spreading centers, show that the variations in strength and form of the Moho reflection event are in most cases primarily caused by lithologic variations within the MTZ. However, the diminished Moho reflection amplitude can also be caused by a combination of rough basement topography, lateral variation within the upper crustal structure, and the use of a reflection travel time equation that does not fully model these crustal complexities ${ }^{4}$. Fig. 2 and the information 
presented in the following text show that our time images provide high-quality information about the MTZ geometry.

2. Sub-Moho reflection events. The subcrustal events presented in Fig. 2b, and shown in greater detail in Fig. S1a, are reflections and not scattered energy because bathymetry maps compiled for this area from various bathymetric data ${ }^{5}$, including swath mapping during the EW0207 cruise, show a very flat, smooth and sedimented seafloor. Even the igneous basement and layer 2A/2B events are smooth and sub-horizontal. Additional support for the deep reflection origin of the imaged events is provided both by partial offset stacks in Fig. S2, which show similarly shaped events and high-velocity edge diffractions for all offset ranges, and by the full stack shown in Fig. S1b. Although no prestack or poststack autoscaling, migration and coherency filtering were applied to the data shown in Fig. S1b, the deep MTZ reflections strongly stand out. The imaged events are not multiples, because short period multiple energy is not observed within the crust and primary multiples arrive at a later recording time. Neither are they residual energy from previous shots, as wrap-around multiples in our data cannot be aligned for stacking because of their varying trace-to-trace arrival times in CMP gathers due to shooting "by distance" (for more details see Fig. S3). Furthermore, the seafloor is shallow relative to the average shooting interval of $\sim 15 \mathrm{~s}$, and it is only the fifth primary multiple series from the previous shot that has some potential to contaminate the imaged MTZ reflections. However, this late multiple series appears to have very little energy. Even the fourth primary multiple series from the previous shot, that should start to arrive within the water column at about $2.5 \mathrm{~s}$, is not visible in the data. Finally, Geological Survey of Canada NE-trending seismic profile $1989-15$ that forms a $\sim 60^{\circ}$ angle 
with line 17-3-1 (Fig. S4), images a thick and complex MTZ $\sim 5-15 \mathrm{~km}$ north of the subcrustal reflection events presented Figs $2 \mathrm{~b}$ and S1. Analysis of the survey characteristics and the geometry of these events on both profiles indicates that they are not side-scattered or multiple energy but deep reflections that could originate within the same thick MTZ. However, because the two profiles do not cross, the single thick MTZ origin for the observed reflections is not possible to conclusively determine.

3. Validity of applied AVO study. Prestack signal to noise ratio for the deep MTZ events is too low for the standard AVO/AVA analysis. However, signal reflected from these deep interfaces is already clearly visible on partially stacked CMP gathers (Fig. S5). This allows for a modified approach to extracting physical properties on partially stacked data described within the main body of the paper. The MTZ events observed in Figs $2 \mathrm{~b}$ and S1 are likely a product of constructive interference between the reflections from the top and the bottom of the sills. The wavelet shape and polarity for these events differ from that observed at simple interfaces. This constructive interference should not affect our AVO study because change in the absolute reflection amplitude as a function of the source-receiver offset for these deep thin layers embedded into homogeneous medium, is for practical purposes identical to that for the corresponding single top or bottom interface. The sill thickness to depth ratio for these events is less than 0.01 and ray paths for the reflections from the top and the bottom of the sill, for a particular source-receiver pair, are practically identical and require no differential normal moveout before stacking.

4. Deep imaging challenges. The thick MTZs marked in Fig. 1 in orange are characterized by Moho and sub-Moho reflection events that are smaller, weaker and less prominent than that shown in Figs $2 b$ and S1a. Because of their low signal to noise ratio and because of various imaging challenges in the study area, subcrustal origin of some of these events is less certain. 
Imaging of subcrustal reflections originating in the vicinity of the ridge axis is particularly challenging for several reasons. (a) Ridge axis is the area where amplitude attenuation is likely to be large both through layer $2 \mathrm{~A}$ and deeper, where seismic tomography results suggest that the hot rock area with a small percentage of melt extends up to $5 \mathrm{~km}$ from the ridge axis. Strong reflection coefficient at the potential boundary between gabbro-melt sill and host dunite or residual mantle peridotite is not sufficient for imaging if the acoustic energy cannot penetrate to the Moho depths. (b) Ridge axis area along our crossings is often characterized by topography that is rougher than at the flanks. Lateral velocity variations caused by a rougher seafloor further complicate data analysis and, for the time processing method that we applied, can lead to suboptimal images. (c) Ridge axis area is usually characterized by the shallowest seafloor and primary multiple energy arrives at early times, in a number of cases making the analysis of sub-Moho reflections impossible. (d) Sills thinner than some $20 \mathrm{~m}$ probably cannot be imaged with our data because of the destructive interference between the top and the bottom interface reflection. Therefore, variations in the sill thickness in general have a significant impact on the continuity of the imaged subcrustal reflections.

\section{Supplementary References}

1. Harding, A. J., Kent, G. M. \& Orcutt, J. A. A multichannel seismic investigation of upper crustal structure at 9 degrees $\mathrm{N}$ on the East Pacific Rise; implications for crustal accretion. $J$. Geophys. Res. 98, 13925-13944 (1993).

2. Collins, J. A., Brocher, T. M. \& Karson, J. A. Two-dimensional seismic reflection modeling of the inferred fossil oceanic crust/mantle transition in the Bay of Islands Ophiolite. J. Geophys. Res. 91, 12520-12538 (1986).

3. Brocher, T. M., Karson, J. A. \& Collins, J. A. Seismic stratigraphy of the oceanic Moho based on ophiolite models. Geology 13, 62-65 (1985). 
4. Babcock, J. M. Magma chamber structure and Moho reflections along the East Pacific Rise. PhD thesis, UCSD - Scripps, 1-244 (1997).

5. Zühlsdorff, L. et al., Site surveys for IODP Expedition 301: ImageFlux (SO149) and RetroFlux (TN116) expeditions. Proc. Integ. Ocean Drill. Prog. Initial Rept., submitted. 6. McBride, J. H. Hobbbs, R. W., Henstock, T. J. and White, R. S. On the "wraparound" multiple problem of recording seismic reflections in deep water. Geophysics 59, 1160-1165 (1994).

\section{Supplementary Figures}

Five supplementary figures with captions accompany Supplementary Information text. 
Nedimovic et al., Fig. S1
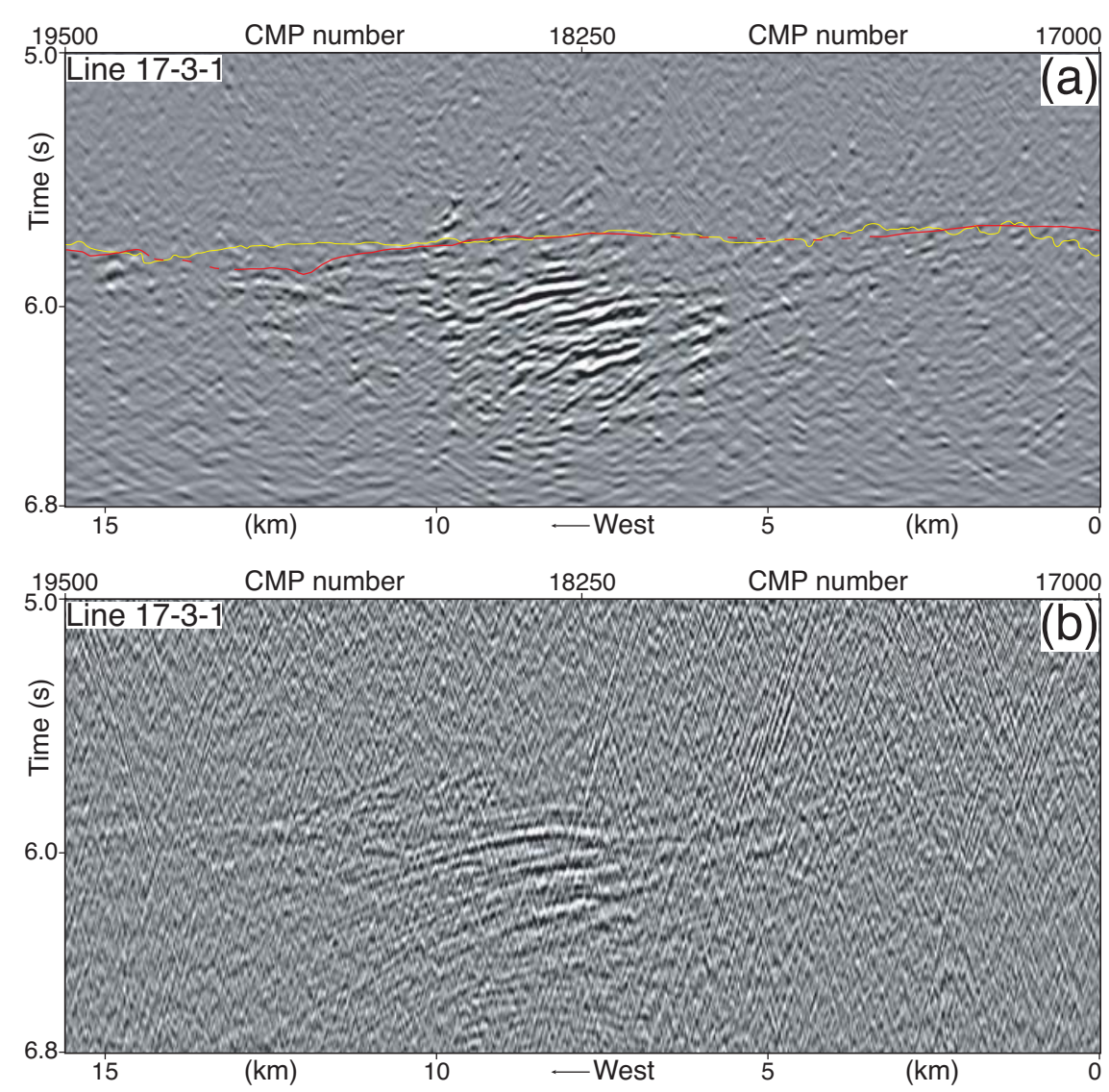

Fig. S1. (a) A close-up look on the most extensive series of subcrustal reflection events recorded during the EW0207 cruise and shown at larger scale in Fig. 2b. The distance to depth ratio is about 1:1. Our interpretation of the Moho discontinuity location is shown with a continuous red line; dashed where inferred. The yellow line is the igneous basement pick delayed by $2080 \mathrm{~ms}$, the average two-way travel time through the oceanic crust in the study area. (b) Stack of the same part of profile 17-3-1 shown in (a). Unlike for (a), which included automatic gain control, the only amplitude balancing applied to the data before stack was done to remove the source and receiver inconsistencies, and to correct for the effects of the geometrical spreading. Furthermore, the data shown in (b) were not subject to any after stack amplitude balancing, migration, and coherency filtering. 
Nedimovic et al., Fig. S2

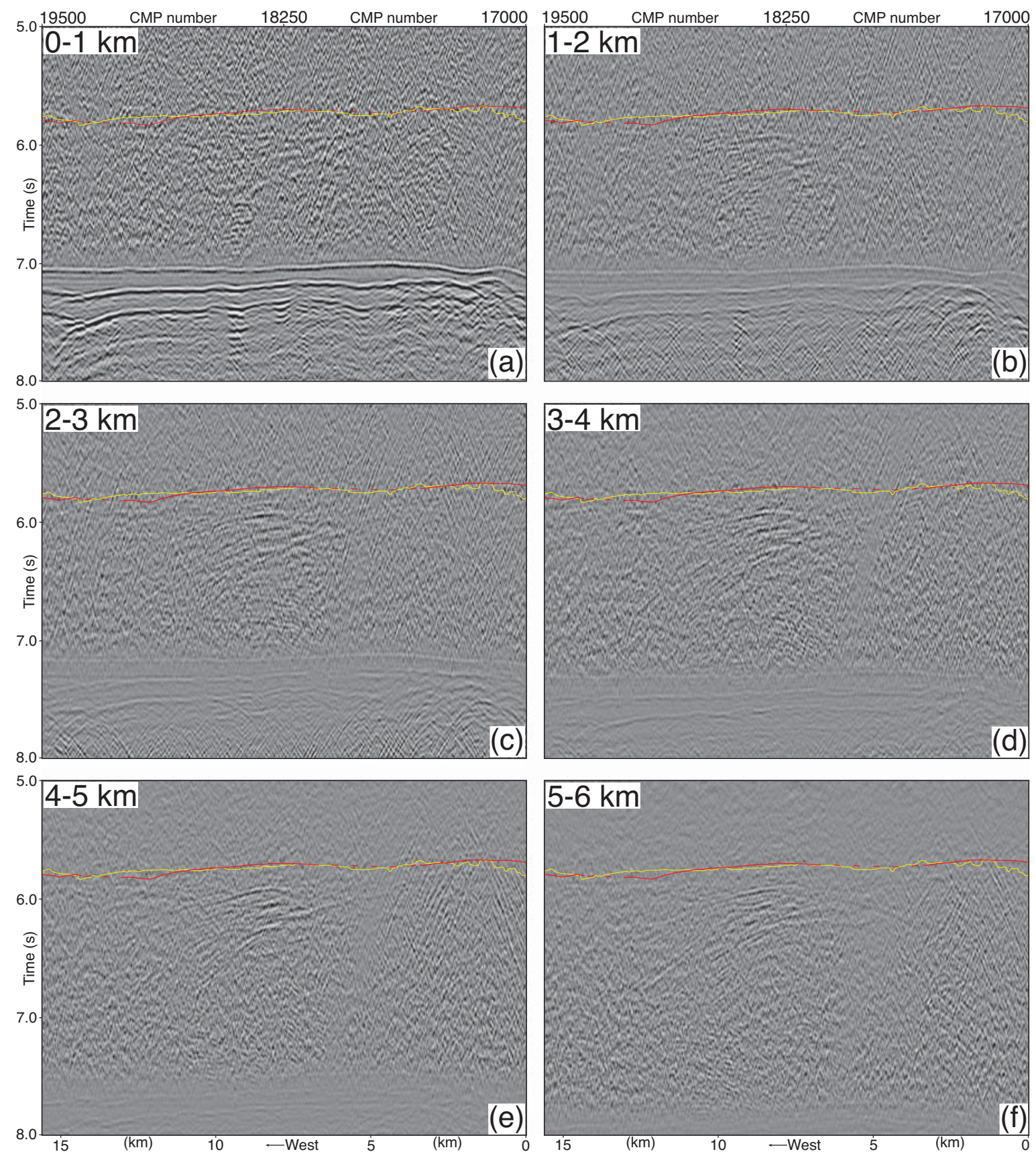

Fig. S2. (a-f) Partial stacks of the line 17-3-1 area displayed in Fig. S1. Subcrustal reflection events cannot be observed on individual prestack data traces but are already visible on the 13-14 trace $(1 \mathrm{~km}$-wide bin) partial stacks. For all offset ranges the presented partial stacks look similar and the edge diffractions are high-velocity signal, lending further support for the conclusions derived from the bathymetry maps that the observed events are reflections and not low-velocity scattered or multiple energy. The subcrustal reflections are weakest in (a), because at short offsets the normal moveout is small and low velocity events such as primary multiples and scattered signal at the seafloor pass the stack filter thus masking reflection events. Note the rapid weakening with increasing offset of the low-velocity primary multiple energy that arrives at $\sim 7 \mathrm{~s}$. 
Nedimovic et al., Fig. S3
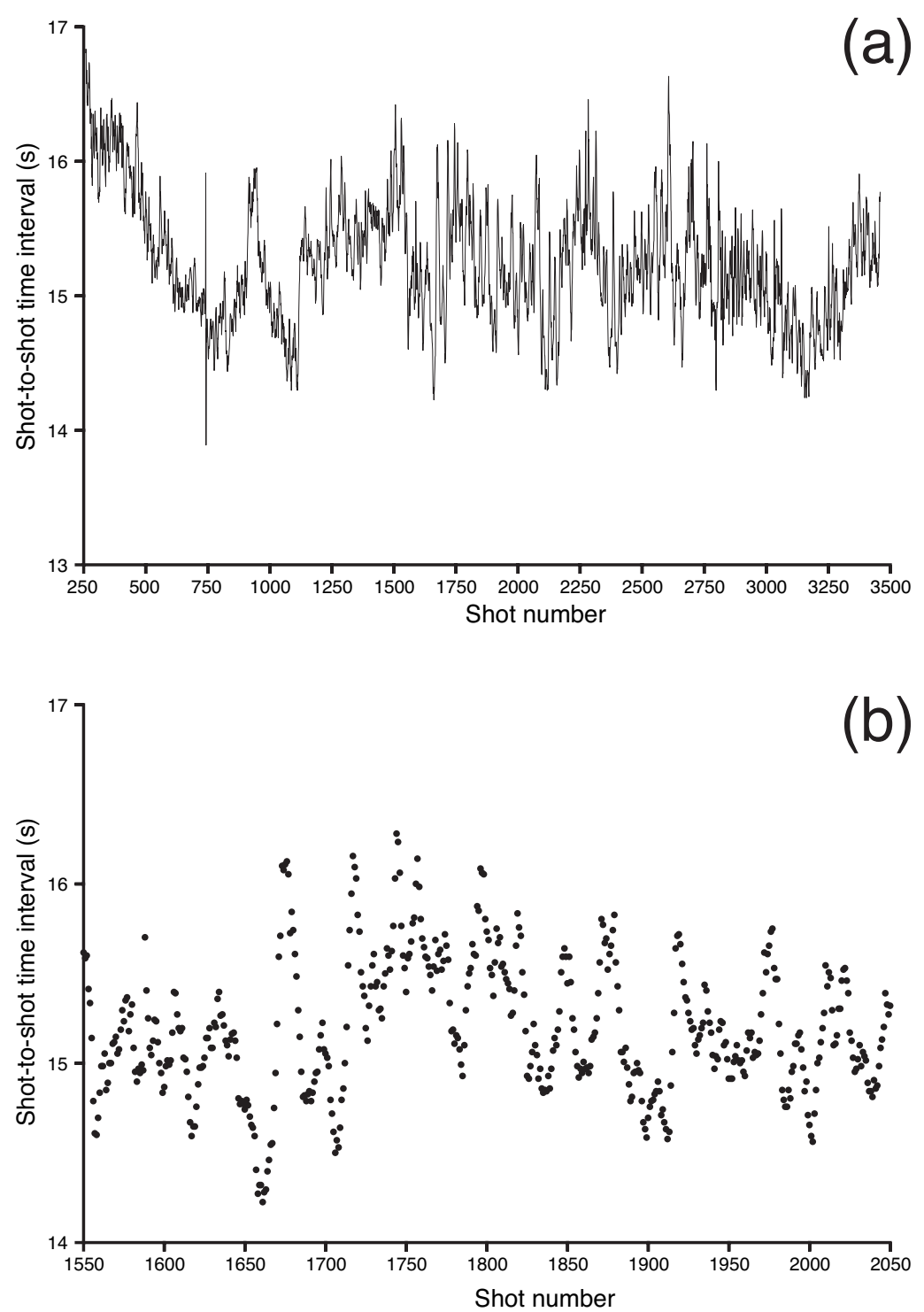

Fig. S3. Shot-to-shot time intervals for segment 3 of line 17-3-1 (a) and for a $\sim 20 \mathrm{~km}$-long section of the same segment centered on the area where the most prominent group of the Moho transition zone reflections is observed (Figs 2b and S1) (b). Shooting "by distance" introduces sufficient jitter in shot-to-shot time intervals that residual energy from previous shots cannot coherently align in CMP gathers for stacking. For example, time between successive shots differed by an average of more than $90 \mathrm{~ms}$ between shot points 1550 and 2050 of segment 3 (b). For some of the earlier surveys shot "by time" (with successive shots fired at a fixed or constant time interval) it has been shown ${ }^{6}$ that wrap-around multiples, or other residual energy from previous shots, may stack coherently under special circumstances. This is particularly true for surveys carried out in deep water. To avoid this problem, early (1975-2000) Lamont acquisition systems included shot time randomization. With the near-worldwide availability of accurate DGPS navigation, shots are now fired "by distance", and additional randomization of shot-to-shot time intervals is not necessary. 
Nedimovic et al., Fig. S4
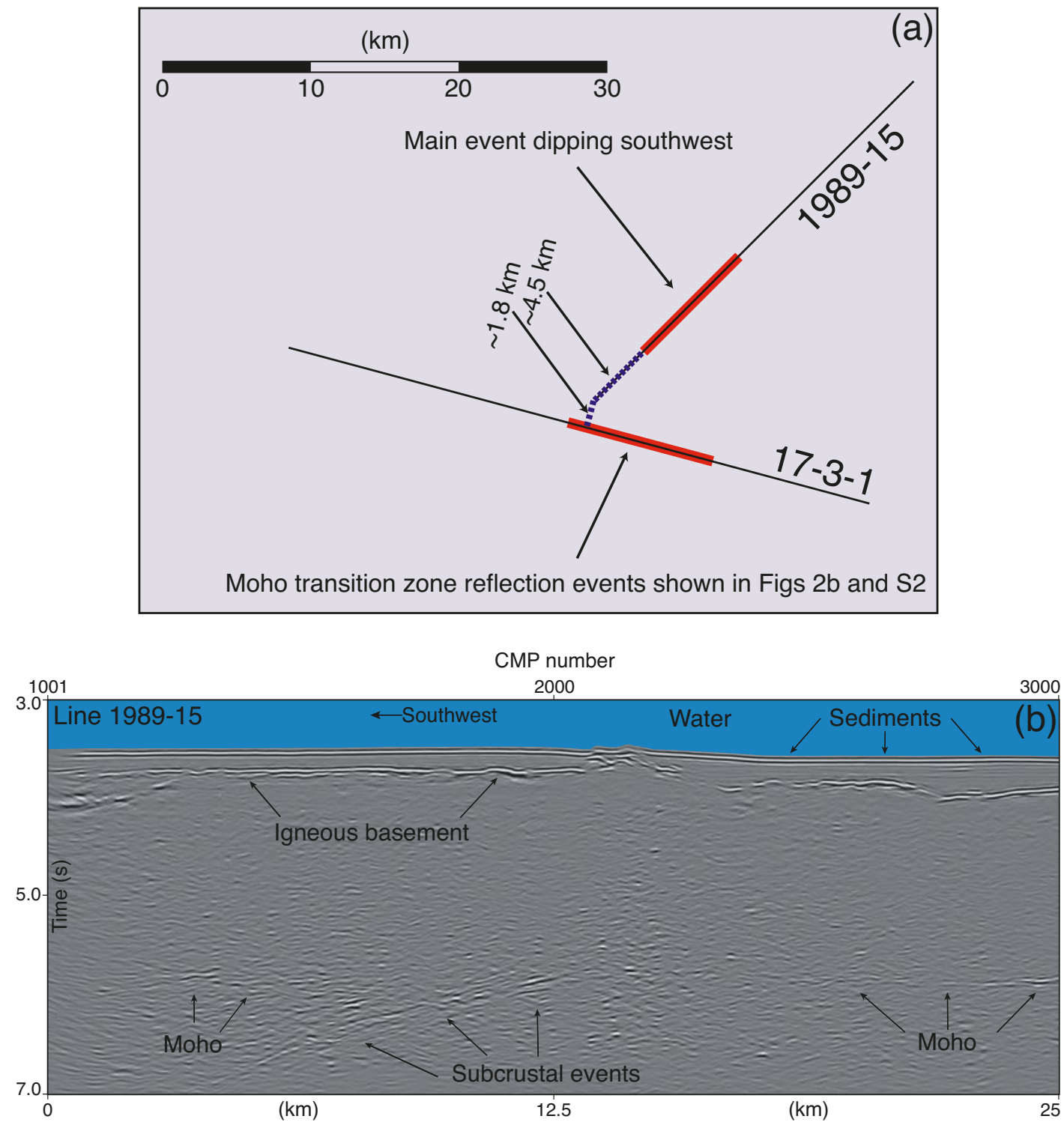

Fig. S4. (a) Plan view of the area where the SW end of the Geological Survey of Canada profile 1989-15 meets the part of the EW0207 profile 17-3-1 characterized by the prominent thick MTZ shown in Figs $2 \mathrm{~b}$ and S1. Note a complex and thick MTZ also at the SW end of profile 1989-15 shown in (b). The approximate extent of the thick MTZs shown in (a) is marked in red on both reflection profiles. Ship tracks are thin black lines. 


\section{Source-receiver offset $(\mathrm{km})$}

Nedimovic et al., Fig. S5
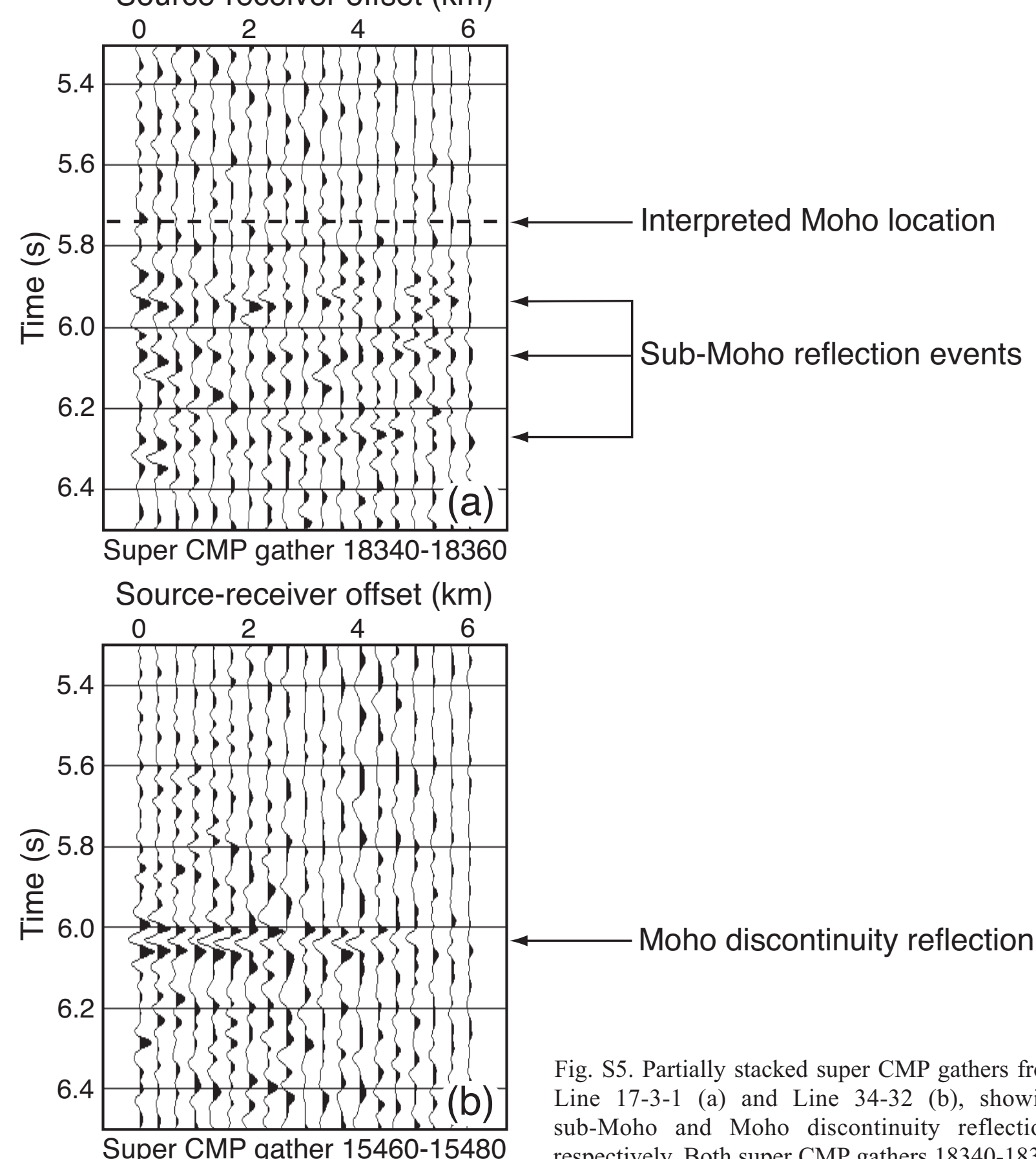

Moho discontinuity reflection

(a) and 15460-15480 (b), are composed of 21 adjacent CMP gathe from both super CMP gathers are presented in Fig. 2. Moho event is not visible in the super CMP gather presented in (a) but its location can be infered from the stacked section shown in Figs $2 \mathrm{~b}$ and S1. The offset window used for partial stacking is $300 \mathrm{~m}$. Our partially stacked super CMP gathers demonstrate that large redundancy of modern MCS data is one of the keys to imaging deep interfaces in the crystalline crust, which are often smaller than the Fresnel Zone and are characterized by rough surfaces that can scatter acoustic energy rather than reflect it. Although the signal-to-noise ratio within the prestack data for these deep events is low and the signal is not optimally aligned for stacking, the imaged relections are strong and easily recognized in partial offset stacks of combined adjacent CMP gathers. 